alternative being mixed cropping as an insurance against climate failure. Intimately bound up with the success were the emerging techniques of irrigation, terracing, fallowing, weed control and manuring. A major question in resolving the development of rice cultivation is concerned with the contrasting styles of upland and lowland rice cultures, although their relative antiquities, Chang feels, cannot be resolved at present.

The contributions given by $\mathrm{E}$. S. Higgs and Heather Jarman (University of Cambridge) were both concerned with the development of prehistoric agriculture in Europe, either in the uplands or lowlands (where resources tend to differ from one another). Both were involved with the construction of a theoretical framework concerned with possible changes in relations between populations, natural resources and the level of technology. Patterns of agricultural exploitation, they consider, can be demonstrated from divergent regions of Europe. This territory approach is one of the methods particularly adopted by the Cambridge group, and deserves fully testing on actual site data. Unfortunately theoretical frameworks, although worth exploring, arc always in danger of showing the 'average' rather than the highly variable nature of human society.

As a classical archaeologist, J. Boardman (University of Oxford) provided something of a contrast to the majority of other papers. He demonstrated that this zone of archaeology can contribute usefully to a full reconstruction of plant use in relation to earlier human cultures. Although the olive was dealt with in particular detail, various plants and animals could have been similarly treated. Wild olive grew freely in the early Mediterranean, and its value was well recognised by Bronze Age times-when it became important economically in Greece at least. The elaboration of a material culture to cope with the extraction and uses of olives even included special scrapers for the removal of oil after its application to the body!

The concluding paper of the conference provided a worthwhile contrast, more precisely an alternative viewing of the relationship between man and his environment during these earlier cultural phases. G. W. Dimbleby (University of London) pointed out that although during his evolution man had 'freed' himself to some extent from his natural environment. he has probably influenced it profoundly in some areas -although to a varying degree depending on the nature of the human activity within the ecosystem. In particular agriculture, both pastoral and arable, has been a significant imposed change on the ecosystem-with resultant changes to the components of the microclimate and vegetation. Eventually, even soil degradation and marked erosion can occur, and then it is increasingly difficult for regeneration processes to occur. Holocene environments, then, are by no means in a state of equilibrium, and some are far more 'brittle' than others. It would also appear that often the early farmers were in fact concentrating on these brittle environments, such as savanna wsodland, steppe, or light deciduous forest-and there is growing evidence of the detrimental side effects which eventually occurred.

\section{X-ray diffraction studies of biomembranes}

\section{from A. E. Blaurock and W. R. Lieb}

Membrane biochemists, following the maxim that "the proper study of mankind is man", have studied the human red blood cell membrane in great detail. Unlike other human tissues, blood can be obtained in large quantities without harming the donor. There is the added attraction that the red cells have no internal membranes to complicate matters. And pure cell membranes are easily obtained by haemolysis, that is by osmotically bursting the cells and extruding their contents into hypotonic solutions. The resulting 'ghosts' are single-walled sacs of cell membranes.

It has been found that most of the ghost protein will react with aqueous labelling reagents and enzymes when these are allowed to enter the sac, but little reacts when these are kept outside. The inference which membrane biochemists have drawn from such results is that most of the protein is associated with the inner, cytoplasmic surface of the membrane (for a recent review, see Steck, J. Cell Biol., 62, $1-19 ; 1974)$. In addition, about a third of the total protein mass is released at very low ionic strength without detergents, suggesting a location largely extrinsic to the lipid bilayer. Interestingly, this superficial protein (mainly 'spectrin') reacts exclusively with inside reagents. The picture that emerges is of a very asymmetric membrane, with more protein on the inside than on the outside and with much of this inner protein lying superficially at the cytoplasmic surface. With this picture in mind, it is surprising that a recent $X$ ray diffraction study by Stamatoff, Krimm and Harvie (Proc. natn. Acad. Sci. U.S.A., 72, 531-534; 1975) concludes that the electron density profile for the ghost membrane is symmetrical.

Although ghost sacs in unoriented dispersions have been looked at by Xray diffraction, Wilkins et al. (Nature new Biol., 230, 72-76; 1971) also pointed out the advantages that would come from arranging the membranes in

\title{
A new anti-sickling agent?
}

from a Correspondent

Current interest in the undamental aspects of the aggregation of deoxy sickle-cell haemoglobin is but one approach to the serious practical problems which arise in the management of sickle cell anaemia patients. Side by side with studies on the behaviour of deoxy $\mathrm{Hb}-\mathrm{S}$ there have been attempts to devise therapeutic methods for reducing or abolishing the sickling process in vivo. Proposals to use urea and, more recently, cyanate as anti-sickling agents have been widely publicised and their effects on the aggregation of deoxy Hb-S are susceptible to rational explanation. The value of cyanate as a long-term anti-sickling agent is now being very carefully assessed by US workers. Less has been heard recently of the antisickling properties of steroids, although both testosterone and progesterone have been tested in vitro and in vivo and claimed to have some degree of efficiency.

Now comes the news of an entirely novel type of anti-sickling agent, found in aqueous extracts of Fagara zanthoxyloides root. In their first publication in a European journal, a group of workers in Ile-Ife and Ibadan, Nigeria, report some toxicological and preliminary clinical trials of this material (Isaacs-Sodeye, Sofowara, Williams, Marquis, Adenkunie and Anderson, Acta haemat., $53,158 ; 1975)$. The roots in question are used as chewing sticks in the Western State of Nigeria and then the fibrous end thus produced is used to brush the teeth. There is evidence of antimicrobial activity against oral microorganisms in the root extract and no folk history of side effects.

The paper intimates favourable toxicological findings in limited tests on $F$. zanthoxyloides extracts, and a significant diminution in the incidence of painful episodes (sicklecell crises) in the few patients treated. Comprehensive clinical trials at many centres in Nigeria are now being organised. The results of these trials will be awaited with great interest, especially as it is stated that a pure component of the root extract with potent anti-sickling activity can also be synthesised in the laboratory. 